\title{
Impact of androgen deprivation therapy on sexual function: a response
}

\author{
Erik Wibowo $^{1}$, Richard Wassersug ${ }^{1,2}$, Karen Warkentin ${ }^{3}$, Lauren Walker ${ }^{4}$, John Robinson ${ }^{5}$, Lori Brotto ${ }^{6}$ \\ and Thomas Johnson ${ }^{7}$
}

Asian Journal of Andrology (2012) 14, 793-794; doi:10.1038/aja.2012.60; published online 16 July 2012

Dear Editors,

We appreciate the growing interest in sexual health for cancer patients and survivors. Mazzola and Mulhall's recent paper, ${ }^{1}$ however, creates the impression that rewarding sex is not possible for prostate cancer patients on androgen deprivation therapy (ADT). This impression, we believe, is not scientifically justified, and may be a disservice to prostate cancer patients and their partners in that it could act as a negative placebo, i.e., the opposite of an aphrodisiac. It was unfortunate that the authors did not use their paper to explore positive pathways for sexual interaction and arousal among ADT patients. Instead, readers may be left with a rather discouraging outlook on the prospect of sexual intimacy and pleasure for androgen-deprived cancer patients.

Historically and culturally, there are data to show that castrated males are not obligatorily asexual. While most historical eunuchs were castrated before puberty, they were considered to be everything from asexual to hypersexual depending on the culture. ${ }^{2}$ Postpubertal eunuchs, whether the one million Hijra of India ${ }^{3}$ or the contemporary Westerners castrated (frequently by self-surgery) as treatment for Male-to-Eunuch gender dysphoria, ${ }^{4}$ continue to display both sexual interest and ability.

Our data show that many modern-day voluntary eunuchs maintain not only sexual interest, but also sexual activity (manuscript in prep.). Of 203 adult males who were voluntary castrated (chemically or physically) and either used no hormone supplementation or took minimal estrogen to prevent osteoporosis and hot flashes, $4 \%$ reported an increase in sexual activity, either masturbation or with a partner, $24 \%$ reported no change and $45 \%$ reported some reduction in sexual activity. Only $27 \%$ reported becoming asexual, a result that many of them had sought. As reported previously, ${ }^{5}$ these men ranged in age from $18+$ to their 80 s, with a mean age in the mid-forties. Sexual function was self-reported in a brief questionnaire that we designed to acquire data on sexual fantasies, sexual attraction and sexual activity in the months before and after castration. Based on the information that the respondents provided us, we could assume that the vast majority of these men were functionally intact before being androgen-deprived.
One contributing factor for androgen-deprived males to maintain sexual interests is likely to be estrogen supplementation. Wibowo et al. ${ }^{6}$ recently reviewed a wealth of animal studies showing that estrogen in androgen-deprived males raises libido above castrate levels. Furthermore, Wibowo et al. have now expanded this review to include castrated males of 27 species ranging from amphibians to mammals. Of these, 14 (13 mammalian) species exhibit elevated sexual interest following exogenous estrogen administration. This further strengthens the notion that androgen deprivation needs not terminally eradicate libido. We acknowledge, though, that this effect is not universal and differences between species could be attributable to innate species differences, differences in the type and dose of estrogen used and in the pathways used for estrogen administration.

Estrogen can also preserve libido to some extent in cancer patients on ADT. Studies by Ellis and Grayhack $(1963)^{6}$, Bergman et al. $(1984)^{7}$, Davidson et al. $(1983)^{8}$ and Brett et al. $(2007)^{9}$ (all cited in Wibowo et al. ${ }^{10}$ ) collectively indicate that patients taking high-dose estrogen were more sexually active than those who were surgically castrated and receiving no supplemental hormones. Furthermore, libido is better preserved in prostate cancer patients on anti-androgen monotherapy (who subsequently have elevated estradiol levels from the aromatization of testosterone) than those who are surgically castrated. ${ }^{11}$ Wassersug and Gray ${ }^{12}$ independently noted that maleto-female transsexuals, who are castrated and take supplemental estrogen, are more likely to be sexually active than are androgen-deprived prostate cancer patients, who typically take no supplemental estrogen.

These studies support the hypothesis that estrogen can elevate libido in androgen-deprived men. We recognize that this estrogenic effect is not as strong as androgens in promoting sexual interest. Additionally, as with testosterone itself, it is likely to be confounded by factors such as age and also whether the person was sexually active prior to ADT treatment.

In addition, regardless of erectile functioning, androgen-deprived cancer patients need not be anorgasmic. Warkentin et al. ${ }^{13}$ published a case study of an androgen-deprived male who reported being orgasmic. We have recently obtained physiological data from the patient

${ }^{1}$ Department of Anatomy \& Neurobiology, Dalhousie University, Halifax, NS B3H 4R2, Canada; ${ }^{2}$ Men's Health Initiative of B.C., Department of Urologic Sciences, University of British Columbia, Vancouver, BC V5Z 1M9, Canada; ${ }^{3}$ Department of Biology, Boston University, Boston, MA 02215, USA; ${ }^{4}$ Department of Psychology, University of Calgary, Calgary, AB T2N 1N4, Canada; ${ }^{5}$ Department of Psychosocial Resources, Tom Baker Cancer Centre, Calgary, AB T2S 3C1, Canada; ${ }^{6}$ UBC Sexual Health Lab, Gordon \& Leslie Diamond Health Care Centre, Department of Obstetrics/Gynecology, Division of Gynecologic Oncology, Vancouver, BC V5Z 1M9, Canada and ${ }^{7}$ Department of Anthropology, California State University, Fulton, CA 95439-0050, USA

Correspondence: Dr T Johnson (twj@sonic.net)

Received: 22 February 2012; Revised: 10 April 2012; Accepted: 16 May 2012; Published online: 16 July 2012 
discussed in Warkentin et al. ${ }^{13}$ which confirm that there are spastic contractions in the patient's pelvic floor synchronous with his reports of orgasm. It is noteworthy that patient uses an external penile prosthesis and his ability to achieve orgasms appears to be dependent on the multisensory integration of total body and not just genital stimulation. A discussion of this method for maintaining a satisfying sex life was unfortunately overlooked in both Mulhall's 2010 book Saving Your Sex Life: A Guide for Men with Prostate Cancer, and the current paper.

Other studies have reported some prostate cancer couples maintaining a sex life while on ADT. ${ }^{14}$ The sample, although small, suggests that maintaining some level of sexual intimacy is both possible and satisfying. It should be acknowledged that humans are motivated to engage in sexual activity for a variety of reasons, not because of sexual urges alone. ${ }^{15}$ For example, despite a lack of libido, some patients remain sexual for the benefit of their partners. Assessments of libido do not necessarily equate with ability and/or motivation for maintaining sexual activity.

In sum, there is far more to male sexuality than erectile function and libido, and lack of testosterone needs not inevitably eliminate pleasurable sexual experiences. Impressions, like the one made by Mazzola and Mulhall, ${ }^{1}$ about the hopelessness of maintaining a rewarding sex life may in fact contribute to the finding that many couples do abandon their sex lives after being told to expect failure. ${ }^{14}$ Sadly, none of the papers mentioned above are discussed by Mazzola and Mulhall. ${ }^{1}$ To ignore this literature is, we believe, a disservice to the many couples who are trying to maintain a rewarding sexual life in the presence of $\mathrm{ADT}$.

\section{AUTHOR CONTRIBUTIONS}

All authors contributed to the intellectual content and drafting of the manuscript.

\section{COMPETING FINANCIAL INTERESTS}

Authors declare no competing financial interest.

\section{ACKNOWLEDGMENTS}

Erik Wibowo is supported by a trainee award from The Beatrice Hunter Cancer Research Institute with funds provided by The Canadian Cancer Society, Nova Scotia Division.

1 Mazzola CR, Mulhall JP. Impact of androgen deprivation therapy on sexual function. Asian J Androl 2012; 14: 198-203.

2 Aucoin MW, Wassersug RJ. The sexuality and social performance of androgendeprived (castrated) men throughout history: implications for modern day cancer patients. Soc Sci Med 2006; 63: 3162-73.

3 Reddy G. With Respect to Sex: Negotiating Hijra Identity in South India. Chicago, IL: Chicago University Press; 2005.

4 Wassersug RJ, Johnson TW. Modern-day eunuchs: motivations for and consequences of contemporary castration. Perspect Biol Med 2007; 50: 544-56.

5 Johnson TW, Brett MA, Roberts LF, Wassersug RJ. Eunuchs in contemporary society: characterizing men who are voluntarily castrated (part I). J Sex Med 2007; 4: 930-45.

6 Ellis WJ, Grayhack. Sexual function in aging males after orchiectomy and estrogen therapy. J Urol 1963; 89: 895-9.

7 Bergman B, Damber JE, Littbrand B, Sjogren K, Tomic R. Sexual function in prostatic cancer patients treated with radiotherapy, orchiectomy or oestrogens. Br J Urol 1984; 56: 64-9.

8 Davidson JM, Camargo C, Smith ER, Kwan M. Maintenance of sexual function in a castrated man treated with ovarian steroids. Arch Sex Behav 1983; 12: 263-74.

9 Brett MA, Roberts LF, Johnson TW, Wassersug RJ. Eunuchs in contemporary society: expectations, consequences, and adjustments to castration (part II). J Sex Med 2007; 4: 946-55.

10 Wibowo E, Schellhammer PF, Wassersug R. Role of estrogen in normal male function: clinical implications for patients with prostate cancer on androgen deprivation therapy. J Urol 2011; 185: 17-23.

11 Iversen P. Quality of life issues relating to endocrine treatment options. Eur Urol 1999; 36 (Suppl 2): 20-6.

12 Wassersug RJ, Gray R. The health and well-being of prostate cancer patients and maleto-female transsexuals on androgen deprivation therapy: a qualitative study with comments on expectations and estrogen. Psychol Health Med 2011; 16: 39-52.

13 Warkentin KM, Gray RE, Wassersug RJ. Restoration of satisfying sex for a castrated cancer patient with complete impotence: a case study. J Sex Marital Ther 2006; 32: 389-99.

14 Walker LM, Robinson JW. A description of heterosexual couples' sexual adjustment to androgen deprivation therapy for prostate cancer. Psychooncology 2011; 20: 880-8.

15 Meuleman EJ, van Lankveld JJ. Hypoactive sexual desire disorder: an underestimated condition in men. BJU Int 2005; 95: 291-6. 